Bond University

Research Repository

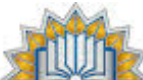 \\ *** BOND \\ UNIVERSITY
}

\section{Lack of a significant legacy effect of baseline blood pressure 'treatment naivety' on all-cause and cardiovascular mortality in the Antihypertensive and Lipid-Lowering Treatment to Prevent Heart Attack Trial}

Ho, Chau L B; Breslin, Monique; Chowdhury, Enayet K; Doust, Jenny; Reid, Christopher M; Davis, Barry R; Simpson, Lara M; Nelson, Mark R

Published in:

Journal of Hypertension

DOI:

10.1097/HJH.0000000000002280

Licence:

Other

Link to output in Bond University research repository.

Recommended citation(APA):

Ho, C. L. B., Breslin, M., Chowdhury, E. K., Doust, J., Reid, C. M., Davis, B. R., Simpson, L. M., \& Nelson, M. R. (2020). Lack of a significant legacy effect of baseline blood pressure 'treatment naivety' on all-cause and cardiovascular mortality in the Antihypertensive and Lipid-Lowering Treatment to Prevent Heart Attack Trial. Journal of Hypertension, 38(3), 519-526. https://doi.org/10.1097/HJH.0000000000002280

\section{General rights}

Copyright and moral rights for the publications made accessible in the public portal are retained by the authors and/or other copyright owners and it is a condition of accessing publications that users recognise and abide by the legal requirements associated with these rights.

For more information, or if you believe that this document breaches copyright, please contact the Bond University research repository coordinator. 
Title: Lack of a significant legacy effect of baseline blood pressure treatment naivety' on all-cause and cardiovascular mortality in the Antihypertensive and Lipid-Lowering Treatment to Prevent Heart Attack Trial (ALLHAT)

Author and affiliations: Chau L.B. HOa , Monique BRESLINª, Enayet K. CHOWDHURY $^{b, c}$, Jenny DOUST ${ }^{d}$, Christopher M. REID ${ }^{b, c}$, Barry R. DAVIS ${ }^{\text {, Lara }}$ M. SIMPSON ${ }^{e}$, Mark R. NELSON a , c.

aMenzies Institute for Medical Research, University of Tasmania, Hobart, Australia bSchool of Public Health, Curtin University, Perth, Australia ${ }^{\circ}$ CCRE Therapeutics, School of Public Health and Preventive Medicine, Monash University, Melbourne, Australia.

${ }^{\mathrm{d} C e n t r e}$ for Research in Evidence Based Practice, Bond University, Gold Coast, Australia

e University of Texas School of Public Health, Houston, United States

Short title: Legacy effects of BP lowering 'treatment naivety'

\section{Acknowledgements}

ALLHAT was supported by contract NO1-HC-35130 with the National Heart, Lung, and Blood Institute (NHLBI). ALLHAT investigators received contributions of study medications supplied by Pfizer (amlodipine besylate and doxazosin mesylate), AstraZeneca (atenolol and lisinopril), and Bristol-Myers Squibb (pravastatin), and financial support provided by Pfizer Inc. For the current study, we gratefully acknowledge the RACGP Foundation and Therapeutic Guidelines Ltd for their financial support of this project. No other funding was received from National Institutes of Health (NIH); Wellcome Trust; Howard Hughes Medical Institute (HHMI); or other granting bodies. We thank Professors Richard McManus, Rod Jackson and Johan Sundstrom for their support.

\section{Conflicts of Interest and Source of Funding}


C.L.B. Ho is a Ph.D. candidate at Menzies Institute for Medical Research, she has received a Ph.D. scholarship from Merle Weaver Postgraduate Scholarship. J.D is funded by the NHMRC CRE grant 1106452. M.R.N has served on advisory boards for Sanofi and Bayer in the last 3 years. For the remaining authors none were declared.

Funding for this analysis was from the RACGP Foundation and Therapeutic Guidelines Ltd.

Corresponding author: Dr. Chau L.B. Ho, Menzies Institute for Medical Research, University of Tasmania, Private Bag 23, Hobart TAS 7001, Australia. Tel: +61406626898. Fax: +61362264734. Email: chau.ho@utas.edu.au.

Word count:4304

Number of tables: 3

Number of figures: 2 .

Number of supplementary digital content files: 0 


\begin{abstract}
Objectives: To investigate legacy effects at 14-years follow-up of all-cause and cardiovascular disease (CVD) mortality in 'treatment naïve'(TN) or 'previous treatment' (PT) groups based on blood pressure (BP) lowering treatment status at baseline.
\end{abstract}

Methods: A post-hoc observational study of the ALLHAT. We excluded participants with a previous history of CVD events. Cox proportional hazard model and $95 \%$ confidence interval $(\mathrm{Cl})$ were used to estimate the effects of TN on mortality outcomes. Also, a subgroup analysis by estimated 10-year Framingham risk score was performed.

Results: In multivariable models adjusting for baseline and in-trial characteristics (BP values and number of BP medications as time-dependent variables), there was no statistically significant difference in 5-year and 14-year all-cause mortality with a hazard ratio (HR) of 0.93 (95\% confidence interval 0.80-1.09) and HR 0.95 (0.881.03) and in 5-year and 14-year CVD mortality HR 0.94 (0.72-1.23) and HR 0.93 (0.80-1.08). In subgroup by absolute CVD risk, no heterogeneity of the association between TN and short- or long-term all-cause or CVD mortality were found. All comparisons are between the TN and PT groups.

Conclusions: Physicians are concerned about 'legacy effects' of not treating individuals with a BP of $140 \mathrm{mmHg}$ or over and low absolute risk. When treatment intensification was taken into consideration in the primary prevention population in this study, no adverse legacy effect as a result of baseline BP 'treatment naivety' was evident in 14 years of follow-up. The non-significant associations were consistent across the CVD risk subgroups. However, the results may be biased due to unobserved residual confounding and therefore should be interpreted with caution.

Key Words: antihypertensive drug, cardiovascular disease, absolute cardiovascular risk, primary prevention, hypertension, all-cause mortality, CVD mortality. 


\section{Introduction}

Contemporary guidelines for the primary prevention of cardiovascular disease (CVD) are predominantly based on absolute CVD risk stratification for drug treatment decision making (e.g. blood pressure or cholesterol-lowering pharmacotherapies), not solely on blood pressure (BP) or blood cholesterol level ${ }^{1-5}$. As per the guidelines ${ }^{1-}$ 3,5 , individuals with a systolic BP above a traditional threshold of $140 / 90 \mathrm{mmHg}$ may not be treated. In current practice, some physicians remain concerned that delays in drug treatment may lead to irreversible target organ damage, so called adverse 'legacy effects'. Two systematic review and meta-analysis ${ }^{6,7}$ have found beneficial 'legacy effects' of BP lowering drug on reduced major CVD events that persisted after the trial termination even when all participants were back to usual care. However, both reviews incorporated primary and secondary population and most of the included trials had no 'actual' placebo or untreated group when previous treatments were continued on top of the randomised group. The PREVEND-IT ${ }^{8,9}$ and Oslo ${ }^{10,11}$ trials in which previous treatment was not permitted showed no significant adverse effects of placebo or no treatment on all-cause and CVD mortality in either 5-year or 10-year periods. Besides, a post-hoc observational study of the Second Australian National Blood Pressure study (ANBP2) ${ }^{12}$ in the elderly aged 6584 years observed a lower risk of all-cause and CVD mortality in 'treatment naïve' group (TN) who had no previous treatment at baseline, although the effects disappeared when the follow-up were extended to 10 years. Thus, adverse 'legacy effect' of delayed BP lowering drug treatment remains inconsistent. Due to the long established association between elevated BP and CVD risk, conducting a study having a placebo or untreated group seems to be ethically impossible. We conducted a similar study that investigated 14-year legacy effect of baseline BP 'treatment naivety' in the Antihypertensive and Lipid-Lowering Treatment to Prevent Heart Attack Trial (ALLHAT). A subgroup analysis by absolute CVD risk was performed to identify if a sub-group of the population may be harmed by delayed therapy.

\section{Methods}

\section{Study design and population}

A post-hoc observational study of the Antihypertensive and Lipid-Lowering Treatment to Prevent Heart Attack Trial (ALLHAT) was conducted ${ }^{13}$. ALLHAT was a 
large multicentre, double-blinded, randomised active-controlled trial with 33,357 participants from 623 North American centres (USA, Canada, Puerto Rico and the US Virgin Islands) aged 55 years or older, with systolic BP ranging from 140 to under 180 and/or diastolic BP ranging from 90 to under $110 \mathrm{mmHg}$ and at least one additional CVD risk factor.

In this current analysis, 17,699 participants were excluded due to pre-existing major CVD events (myocardial infarction or stroke, coronary revascularization, major ST depression or T-wave inversion) and/or insufficient data for post-trial follow-up. This current study was designed as a post-hoc observational study. Participants were categorized by their BP lowering drug treatment status at baseline into a 'treatment naïve' (TN) and 'previous treated' (PT) group. As presented in Figure 1, participants in the TN group had been untreated or treated for less than two months, whereas participants in the PT group had been treated for more than two months and their BP was controlled $(<160 / 100 \mathrm{mmHg}$ ) with fewer than two BP-lowering medications. Before randomisation, all previous treatment was stopped or stepped down for 2-6 weeks. Participants were randomized to chlorthalidone $12.5 \mathrm{mg}$, amlodipine $2.5 \mathrm{mg}$ or lisinopril $10 \mathrm{mg}$ in a ratio of $1.7: 1: 1$ respectively. To obtain the BP treatment target of less than $140 / 90 \mathrm{mmHg}$, randomized drugs were titrated to maximum tolerated doses before adding open-label step 2 agents (atenolol, reserpine and clonidine) or step 3 agent (hydralazine). The in-trial period was 8 years (1994-2002, median time of 4.9 years). After the study completion, participants returned to their usual care and were expected to continue their BP treatment, although there could be changes in treatment regimens. No information on medications, BP levels, outpatient morbidity, or laboratory values was collected in the post-trial phase. Information on mortality outcomes/participants survival were collected during 2006 and 2011 through the National Death Index or Social Security 
Administration. More details on post-trial observation have been previously published ${ }^{14}$. The main outcomes during the in-trial and post-trial periods were allcause and CVD mortality (death due to CHD, stroke, HF, or other CVD).

\section{Subgroup by absolute CVD risk}

To investigate any difference of delayed treatment effects according to absolute CVD risk, we performed a subgroup analysis stratified by absolute CVD risk. The 10-year Framingham risk score $(\mathrm{FRS})^{15}$ was used because it has been widely validated and calibrated in many different populations. Also, 10-year FRS by D’Agostino et al ${ }^{15}$ accounted for effects of BP lowering drug treatment on estimated CVD risk. Due to the variability of 10 -year FRS thresholds used in different settings ${ }^{2}$, 3 , we considered $<20 \%, 20-30 \%$ and $>30 \%$ over 10 years as the conventional cutoff points for low, moderate and high-risk group correspondingly in this analysis.

\section{Statistical analysis}

Differences in baseline characteristics between the TN and PT group were tested by ANOVA test for continuous variables and Chi-square test for categorical variables. Treatment effects were estimated by Cox proportional hazard model (HRs) and $95 \%$ confidence interval $(\mathrm{Cl})$ and were adjusted for age, race, gender, diabetes mellitus (DM), education, body mass index (BMI), current smoking, aspirin use, randomization group, systolic $\mathrm{BP}$, diastolic $\mathrm{BP}$, total cholesterol (TC), glucose, creatinine that were statistically different between PT and TN group (model A). The number of BP lowering drugs used in the in-trial phase and BP recorded from baseline to last visits were added in multivariate models as time-dependent variables (model B). In a sensitivity analysis, further adjusting for high-density lipoprotein cholesterol (HDL-c) or TC was performed. Also, we tested the effects of 'treatment naïve' when removing baseline BPs from multivariate models. 
In the subgroup analysis by absolute CVD risk, interaction among CVD subgroup was tested by a baseline treatment status $\mathrm{x}$ absolute CVD risk stratification term in Cox models. As most of the missing data (BMI, TC), serum creatinine, DM, education status, serum glucose, HDL-c and low-density lipoprotein cholesterol (LDL-c) was less than $10 \%$ except for serum glucose (26\%), missing values were imputed by mean values. The effects were statistically significant at $p$-value 0.05 . All analyses were performed by STATA version 14.0 for Windows.

\section{Results}

\section{Patient characteristics}

The current study included 15,658 participants without previous history of CVD at baseline, approximately $47 \%$ of the total sample size of the original ALLHAT trial (33,357 participants). As provided in Table 1, on average participants were late middle-aged (mean age 65 years), with mildly elevated BP of 146/85 $\mathrm{mmHg}$ and a moderate 10-year FRS of 39\% (66\% were at high baseline risk). Compared with the PT group, TN participants had lower 10-year FRS as they seemed to have more optimal CVD risk profiles (e.g. younger, non-Black, no diabetes, lower BMI, lower TC, lower serum creatinine), except for a higher proportion of current smokers, males, having lower education and higher BP value. After stratification by absolute CVD risk, TN participants still had statistically higher BP, lower BMI, a higher proportion of males, current smokers and non-DM regardless of risk stratifications. When stratified by baseline risk, there were statistically significant differences in age in the low and moderate risk group; race in the moderate risk and high-risk group; education, LDL-c, serum creatinine, aspirin use and FRS for the high-risk group.

As reported in Table 2, after randomization, TN participants had statistically lower 2- and 4-year systolic BP, a higher rate of participants with BP controlled under 
$140 / 90 \mathrm{mmHg}$ after two years treatment and under $160 / 90 \mathrm{mmHg}$ after four years treatment although they were likely to receive a smaller number of study drugs and a lower rate of medication compliance. When analysed by baseline absolute CVD risk, the number of study drugs in the TN group remained statistically smaller than those in the PT group. No substantial difference between TN and PT group in low and moderate risk groups were recorded regarding average in-trial $\mathrm{BP}$, the rate of $\mathrm{BP}$ controlled under $140 / 90 \mathrm{mmHg}$ or under $160 / 90 \mathrm{mmHg}$, 2-year medication compliance except for 4-year compliance in a low risk group. Differences between TN and PT participants in the high-risk group had similar patterns to those reported in the total population.

\section{Association of 'treatment naïve' and mortality (Table 3 and Table 4)}

1,955 total deaths and 675 deaths due to CVD were recorded throughout the in-trial period, increasing to 4,761 and 1,422 respectively in 2006 and 7,714 and 2,126 in 2011. In unadjusted models, there was a statistically lower risk of shortterm heart failure, 10- and 14-year CVD mortality, 14-year all-cause associated with TN group. In model A, after adjustment for major CVD risk factors (age, gender, DM, TC, systolic BP, diastolic BP, smoking status) and significantly different baseline characteristics (race, BMI, education, aspirin use, randomisation group, glucose, creatinine), the association with heart failure was no longer statistically significant. However, the TN group was associated with a lower risk of long-term all-cause mortality, with HR 0.87 (0.79-0.97) for the 10-year phase and HR 0.90 (0.83-0.97) for the 14-year phase, and a lower risk of long-term CVD mortality with HR 0.81 (0.670.98 ) for the 10-year phase and HR 0.85 (0.73-0.99) for the 14-year phase. In model $\mathrm{B}$, when time-dependent variables for BP value and number of in-trial BP lowering drug treatment were added in multivariate models, no difference of short- or longterm mortality outcomes were observed. In subgroup by 10-year Framingham risk score, no heterogeneity of relative treatment effects was recorded in either model $A$ or B. In sensitivity analysis, multivariate models with further adjustment for HDL-C and/or LDL-c did not record any substantial changes to the results seen in model $A$ 
and $\mathrm{B}$. However, $\mathrm{HRs}$ and $95 \% \mathrm{Cl}$ in multivariate models without baseline BPs were substantially consistent with those recorded in model $B$.

\section{Discussion}

In the current post-hoc observational study of the ALLHAT trial, we found no statistically significant difference between participants who were treatment naïve or previously treated in either short- or long-term all-cause or cardiovascular mortality. The risk ratios were substantially consistent among the low, moderate and high CVD risk groups. On average, participants included in this study had moderate 10-year CVD risk of $39 \%$ and mildly elevated BP $146 / 89 \mathrm{mmHg}$. Many differences in baseline characteristics between the PT and TN group were observed. As the analysis included a large sample size and many statistical tests were performed, some false positives were expected. However, some differences in baseline characteristics seemed to be clinically meaningful and relevant. For example, PT participants were more likely to have lower BP, a lower rate of current smoking, and a higher rate of aspirin use. However, they were at higher estimated baseline risk, due to the higher proportion of participants having diabetes. Throughout the in-trial phase (median time 4.9 years), compared to the PT group, the TN group with smaller numbers of medications to reach the treatment target tended to have a larger systolic BP reduction (20 mmHg vs $10 \mathrm{mmHg}$ ). BPs of TN participants seemed to be more controllable than that of PT group because a higher proportion of TN group had controlled BP under $140 / 90 \mathrm{mmHg}(68 \%$ vs $64 \%)$.

In model A adjusting for baseline characteristics including baseline BPs, compared with PT group at a similar BP level, TN group was associated with a 10$13 \%$ lower relative risk of 10 - and 14 - year all-cause mortality, a 15-19\% lower relative risk of 10- and 14- year CVD mortality. The results indicate a 'residual cardiovascular risk' in PT group that is defined as a persisting risk of developing a CVD event despite using evidence-based protective therapy such as BP lowering 
drug treatment ${ }^{16}$. Our results are similar to the findings of 10-year CVD mortality reported in an individual participant-level meta-analysis by Asayama et al ${ }^{17}$ and a prospective cohort study by Blacher et $\mathrm{al}^{18}$. In a meta-analysis of prospective cohort studies in the Japanese general population, Asayama et al found a significantly increased risk of 10-year CVD mortality HR 1.50 (1.36-1.66) in previously treated participants ${ }^{17}$. Also, the PRIME cohort study by Blacher et al observed an increased risk of 10-year CVD mortality RR 1.62 (1.02-2.58) and a non-statistically increased risk of 10-year all-cause mortality RR $1.15(0.89-1.48)$ in the previously treated group $^{18}$. Included participants in these two studies were likely to be younger than those included in our study. The average BPs of the treated group in the Japanese study $(146 / 84 \mathrm{mmHg})$ remained higher than that of the untreated group (132/79 $\mathrm{mmHg}$ ) and $10 \%$ of the included participants had a history of CVD events.

In model B with further adjustment for the varied effects of BP values and the number of study drugs over time (median time 4.9 years), the association between 'treatment naïve' and lower risk of long-term all-cause and CVD mortality in our study was attenuated and became non-statistically significant. This was not done in most of the above or previous cohort studies ${ }^{17-19}$ that conducted a single baseline survey and thus information of BP lowering drug treatment and BP values during follow-up time were not recorded. We speculated that the in-trial treatment is an indicator of the BP difference when the PT group seemed to have more aggressive drug treatment to reach the treatment target. Also, we were concerned that there may be unmeasured confounding by indication: that is doctors or physicians preferentially treat individuals with higher CVD risk profiles (e.g. subclinical vascular damages or family history of CVD) or those who failed to follow lifestyle modifications or were exposed to uncontrolled high BP for longer. If these factors could be controlled, 'residual risk' may become less apparent. In contrast, a similar analysis of ANBP2 ${ }^{12}$ in the elderly (>65 years) found a significantly lower risk of 4-year all-cause mortality with HR 0.63 (0.46-0.86) and 4-year CVD mortality HR 0.47 (0.27-0.81) in TN participants both before and after adjusting for average follow-up BP lowering drug treatments and average follow-up BP values. Participants in ANBP2 were older (mean age 72 years) and had higher baseline BP (mean BP 168/91 $\mathrm{mmHg}$ ) than that of ALLHAT participants, thus they were more likely to show 'residual risk' of BP lowering drug treatment. 
In the subgroup analysis by absolute CVD risk, the analysis recorded no statistically significant heterogeneity of the association between 'treatment naïve' and relative risk of short- or long-term mortality. In other words, there was no difference in relative risk of short- or long-term mortality outcomes between PT and TN regardless of baseline estimated 10-year CVD risk stratification. Due to significant differences in baseline characteristics between the PT and TN groups, we did not estimate the absolute risk reduction. In a meta-analysis of randomised controlled trials by Thomopoulos et $\mathrm{al}^{20}$, in absolute terms, 'residual risk' in 5 years estimated by incidence rate of all-cause and CVD mortality in the active treatment group were higher for higher estimated CVD risk subgroup. However, baseline CVD risk estimation in the Thomopoulos et al analysis was based on the actual incidence of death rates due to CVD observed in the control groups of the trials. Of note, the control groups could be placebo, no treatment or less intensive treatment and previous BP lowering drug treatment may have continued in the trial. Thus the observed CVD risk in these trials may not be applicable to the estimated risk for patients considering treatment. In the HOPE- $3^{21}$ trial in intermediate-risk participants with mean BP of 138/82 mmHg, no substantial benefit of active treatment was recorded. However, an increased risk of symptomatic hypotension, dizziness and light-headedness were observed after a median follow-up time of 5.6 years. Similarly, PREVEND-IT ${ }^{8,9}$ and Oslo ${ }^{10,11}$ trials that had relatively low risk population did not record substantial benefits on major CVD event in either 5-year or 10-year periods. However, statistically significant effects may not have been achieved because these studies were likely to have lacked statistical power (a small number of events were seen in this low CVD risk setting).

\section{Limitations}

ALLHAT was one of the largest hypertension randomised controlled trials ever conducted. After excluding those with a baseline history of CVD, 15658 participants were included in the present study. Details of BP lowering drug treatment and BP values were closely monitored throughout the in-trial period (median time 4.9 years) and the varying effects of these characteristics over time were adjusted in Cox regression models. ALLHAT had a very small number of missing values for baseline characteristics (<15\%) except for serum glucose (26\%). Still, there are some limitations in our analysis. 
Our study was biased by 'confounding by indication' as mentioned above. Also, we were uncertain of the use of concomitant treatment such as lipid lowering drug treatment or aspirin. The study was limited to long-term mortality events; longterm non-fatal CVD events such as CHD or stroke were not recorded, and these are also a concern for physicians when not treating BP at a traditional systolic BP threshold of $140 \mathrm{mmHg}$. Lack of information on the period of untreated status in TN group is one of the major limitations. We considered that these untreated participants may have not been diagnosed with hypertension or they did not adhere to the treatment. Also, they could be underlying lifestyle modifications although TN participants were likely to have clinically higher rate of smoking compared to PT participants (40\% vs $28 \%$ ). There were some clinical differences in baseline characteristics between TN and PT group as mentioned. While statistical adjustments were done, such adjustments can not fully control for clinical differences and replace randomized observations. This is a post-hoc observational study, and statistical power was reduced. However, the length of the post-trial follow-up increased the number of events and thus partly improved the statistical power. As with all observational studies, the results may be biased by unmeasured residual confounding that increased the imbalance of baseline CVD risk between the PT and TN group. The results should be interpreted with caution.

\section{Conclusions}

When treatment intensification was taken into consideration in the primary prevention population in this study, no adverse legacy effect as a result of baseline BP 'treatment naivety' was evident in 14 years of follow-up. The non-significant associations were consistent across the CVD risk subgroups. 


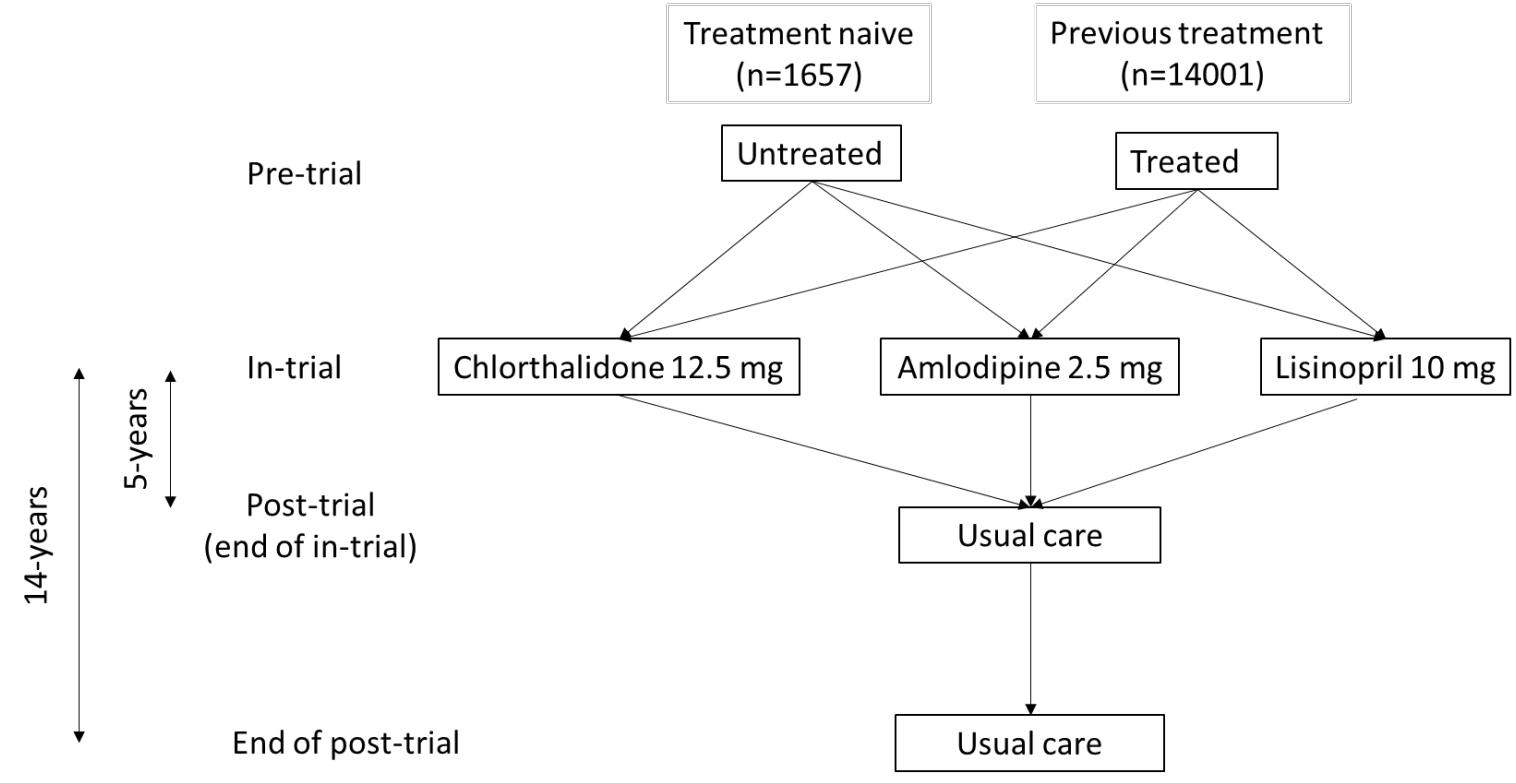

Figure 1 Flow diagram of included participants 
Table 1 Baseline characteristics in total cohort and subgroup by 10-year Framingham risk score

\begin{tabular}{|c|c|c|c|c|c|c|c|c|}
\hline \multirow[t]{2}{*}{ Characteristics } & \multicolumn{4}{|c|}{ TN } & \multicolumn{4}{|c|}{ PT } \\
\hline & Total & Low & $\begin{array}{l}\text { Mode } \\
\text { rate }\end{array}$ & High & Total & Low & $\begin{array}{l}\text { Mode } \\
\text { rate }\end{array}$ & High \\
\hline $\begin{array}{l}\text { Number of } \\
\text { observations, } \mathrm{n}(\%)\end{array}$ & $\begin{array}{l}1657 \\
(10.6)\end{array}$ & $\begin{array}{l}299 \\
(13.6)\end{array}$ & $\begin{array}{l}386 \\
(12.0)\end{array}$ & $\begin{array}{l}972 \\
(9.5)\end{array}$ & $\begin{array}{l}14001 \\
(89.4)\end{array}$ & $\begin{array}{l}1900 \\
(86.4)\end{array}$ & $\begin{array}{l}2819 \\
(88.0)\end{array}$ & $\begin{array}{l}9282 \\
(90.5)\end{array}$ \\
\hline $\begin{array}{l}\text { Age } \\
\text { (mean + SD, years) }\end{array}$ & $\begin{array}{l}64.9 \pm \\
7.4\end{array}$ & $\begin{array}{l}60.6 \pm \\
5.1\end{array}$ & $\begin{array}{l}62.7 \pm \\
6.6\end{array}$ & $\begin{array}{l}67.1 \pm \\
7.6\end{array}$ & $\begin{array}{l}65.7 \pm \\
7.4\end{array}$ & $\begin{array}{l}61.5 \pm \\
5.8\end{array}$ & $\begin{array}{l}63.7 \pm \\
6.8\end{array}$ & $\begin{array}{l}67.2 \pm \\
7.4\end{array}$ \\
\hline Black, $\overline{\%}$ & 37.4 & 53.5 & 38.1 & 32.2 & 41.1 & 50.7 & 46.9 & 37.4 \\
\hline Male, \% & 56.1 & 18.4 & 39.6 & 74.2 & 48.1 & 10.0 & 28.4 & 63.4 \\
\hline Current Smoker, \% & 40.0 & 27.1 & 39.6 & 44.2 & 27.6 & 20.7 & 23.5 & 30.2 \\
\hline $\begin{array}{l}\text { Education } \\
(\text { mean } \pm S D, \text { years })^{*}\end{array}$ & $\begin{array}{l}10.6 \pm \\
4.3\end{array}$ & $\begin{array}{l}10.9 \pm \\
4.0\end{array}$ & $\begin{array}{l}10.8 \pm \\
4.3\end{array}$ & $\begin{array}{l}10.5 \pm \\
4.4\end{array}$ & $\begin{array}{l}10.9 \pm \\
4.0\end{array}$ & $\begin{array}{l}11.0 \pm \\
3.9\end{array}$ & $\begin{array}{l}10.8 \pm \\
3.9\end{array}$ & $\begin{array}{l}10.8 \pm 4 \\
1\end{array}$ \\
\hline $\begin{array}{l}\text { BMl (mean } \pm \text { SD, } \\
\left.\mathrm{kg} / \mathrm{m}^{2}\right)^{*}\end{array}$ & $\begin{array}{l}29.1 \pm \\
6.2\end{array}$ & $\begin{array}{l}30.0 \pm \\
7.4\end{array}$ & $\begin{array}{l}29.6 \pm \\
6.8\end{array}$ & $\begin{array}{l}28.6 \pm \\
5.5\end{array}$ & $\begin{array}{l}30.4 \pm \\
6.5\end{array}$ & $\begin{array}{l}31.1 \pm \\
7.3\end{array}$ & $\begin{array}{l}30.9 \pm \\
7.5\end{array}$ & $\begin{array}{l}30.2 \pm 6 . \\
0\end{array}$ \\
\hline Diabetes* (\%) & 44.3 & 16.2 & 34.4 & 56.1 & 56.7 & 23.0 & 44.8 & 66.7 \\
\hline \multicolumn{9}{|l|}{$\begin{array}{l}\text { SBPs (mean } \pm \text { SD, } \\
m m H g):\end{array}$} \\
\hline $\begin{array}{l}1^{\text {st }} \text { visit } \\
2^{\text {nd }} \text { visit }\end{array}$ & $\begin{array}{l}158 \pm \\
12 \\
156 \pm \\
12\end{array}$ & $\begin{array}{l}155 \pm \\
13 \\
150 \pm \\
12\end{array}$ & $\begin{array}{l}159 \pm \\
12 \\
156 \pm \\
12\end{array}$ & $\begin{array}{l}159 \pm \\
12 \\
158 \pm \\
12\end{array}$ & $\begin{array}{l}143 \pm \\
13 \\
145 \pm \\
15\end{array}$ & $\begin{array}{l}138 \pm \\
14 \\
135 \pm \\
14\end{array}$ & $\begin{array}{l}141 \pm \\
13 \\
141 \pm \\
14\end{array}$ & $\begin{array}{l}145 \pm 13 \\
149 \pm 15\end{array}$ \\
\hline \multicolumn{9}{|l|}{$\begin{array}{l}\text { DBPs (mean } \pm \text { SD, } \\
m m H \text { ): }\end{array}$} \\
\hline $1^{\text {st }}$ visit & $91 \pm 9$ & $92 \pm 9$ & & $\begin{array}{l}90 \pm \\
10\end{array}$ & $\begin{array}{l}83 \pm \\
10\end{array}$ & $83 \pm 9$ & $83 \pm 9$ & $83 \pm 10$ \\
\hline $2^{\text {nd }}$ visit & $90 \pm 9$ & $90 \pm 9$ & $\begin{array}{l}90 \pm \\
10\end{array}$ & $90 \pm 9$ & $\begin{array}{l}85 \pm \\
10\end{array}$ & $\begin{array}{l}82 \pm \\
10\end{array}$ & $84 \pm 10$ & $85 \pm 10$ \\
\hline \multicolumn{9}{|l|}{$\begin{array}{l}\text { Laboratory (mean } \pm \\
\mathrm{SD}, \mathrm{mmol} / \mathrm{L}):\end{array}$} \\
\hline $\begin{array}{l}\text { Fasting Serum } \\
\text { Glucose* }^{*}\end{array}$ & $\begin{array}{l}7.1 \pm 3 . \\
5\end{array}$ & $\begin{array}{l}5.8 \pm \\
2.5\end{array}$ & $\begin{array}{l}6.7 \pm \\
3.5\end{array}$ & $\begin{array}{l}7.7 \pm \\
3.6\end{array}$ & $\begin{array}{l}7.5 \pm \\
3.5\end{array}$ & $\begin{array}{l}6.0 \pm \\
2.6\end{array}$ & $\begin{array}{l}7.0 \pm \\
3.3\end{array}$ & $7.9 \pm 3.6$ \\
\hline $\mathrm{TC}$ & $\begin{array}{l}5.6 \pm \\
1.2\end{array}$ & $\begin{array}{l}5.3 \pm \\
1.0\end{array}$ & $\begin{array}{l}5.4 \pm \\
1.1\end{array}$ & $\begin{array}{l}5.7 \pm \\
1.2\end{array}$ & $\begin{array}{l}5.6 \pm \\
1.1\end{array}$ & $\begin{array}{l}5.3 \pm \\
1.0\end{array}$ & $\begin{array}{l}5.5 \pm \\
1.0\end{array}$ & $5.7 \pm 1.2$ \\
\hline HDL Cholesterol* & $\begin{array}{l}1.2 \pm \\
0.4\end{array}$ & $\begin{array}{l}1.5 \pm \\
0.4\end{array}$ & $\begin{array}{l}1.3 \pm \\
0.4\end{array}$ & $\begin{array}{l}1.1 \pm \\
0.3\end{array}$ & $\begin{array}{l}1.2 \pm \\
0.4\end{array}$ & $\begin{array}{l}1.5 \pm \\
0.5\end{array}$ & $\begin{array}{l}1.3 \pm \\
0.4\end{array}$ & $1.1 \pm 0.3$ \\
\hline LDL Cholesterol* & $\begin{array}{l}3.5 \pm \\
1.0\end{array}$ & $\begin{array}{l}3.2 \pm \\
0.9\end{array}$ & $\begin{array}{l}3.4 \pm \\
1.0\end{array}$ & $\begin{array}{l}3.7 \pm \\
1.0\end{array}$ & $\begin{array}{l}3.5 \pm 1 \\
0\end{array}$ & $\begin{array}{l}3.1 \pm \\
0.9\end{array}$ & $\begin{array}{l}3.4 \pm \\
1.0\end{array}$ & $3.6 \pm 1.0$ \\
\hline $\begin{array}{c}\text { Serum Creatinine* } \\
(\text { mean } \pm S D, \mu \mathrm{mol} / \mathrm{L})\end{array}$ & $\begin{array}{l}86.7 \pm \\
26.5\end{array}$ & $\begin{array}{l}80.5 \pm \\
35.4\end{array}$ & $\begin{array}{l}84.0 \\
+ \\
35.4\end{array}$ & $\begin{array}{l}89.3 \pm \\
26.5\end{array}$ & $\begin{array}{l}88.4 \pm \\
26.5\end{array}$ & $\begin{array}{l}78.7 \pm \\
17.7\end{array}$ & $\begin{array}{l}84.0 \pm \\
26.5\end{array}$ & $\begin{array}{l}92.0 \pm \\
26.5\end{array}$ \\
\hline Aspirin use, \% & 19.4 & 16.4 & 21.8 & 19.4 & 23.6 & 18.9 & 19.7 & 25.8 \\
\hline $\begin{array}{l}\text { Estrogen use in } \\
\text { women, \% }\end{array}$ & 14.7 & 21.7 & 14.6 & 8.0 & 17.4 & 26.2 & 19.8 & 11.7 \\
\hline \multicolumn{9}{|l|}{$\begin{array}{l}\text { Randomization } \\
\text { Treatment Group: }\end{array}$} \\
\hline $\begin{array}{l}\text { Chlorthalidone } \\
\text { Amlodipine }\end{array}$ & $\begin{array}{l}46.0 \\
27.7\end{array}$ & $\begin{array}{l}47.8 \\
26.1\end{array}$ & $\begin{array}{l}47.7 \\
28.5\end{array}$ & $\begin{array}{l}44.9 \\
27.9\end{array}$ & $\begin{array}{l}45.4 \\
27.5\end{array}$ & $\begin{array}{l}45.9 \\
26.7\end{array}$ & $\begin{array}{l}45.3 \\
28.2\end{array}$ & $\begin{array}{l}45.3 \\
27.5\end{array}$ \\
\hline Lisinopril & 26.3 & 26.1 & 23.8 & 27.3 & 27.1 & 27.4 & 26.6 & 27.2 \\
\hline
\end{tabular}




\begin{tabular}{|c|c|c|c|c|c|c|c|c|}
\hline \multirow[t]{2}{*}{ Characteristics } & \multicolumn{4}{|c|}{ TN } & \multicolumn{4}{|c|}{ PT } \\
\hline & Total & Low & $\begin{array}{l}\text { Mode } \\
\text { rate }\end{array}$ & High & Total & Low & $\begin{array}{l}\text { Mode } \\
\text { rate }\end{array}$ & High \\
\hline $\begin{array}{l}\text { Lipid-Lowering } \\
\text { Randomization } \\
\text { Group, \%: }\end{array}$ & & & & & & & & \\
\hline $\begin{array}{l}\text { Pravastatin } \\
\text { Usual Care }\end{array}$ & $\begin{array}{l}14.4 \\
13.5\end{array}$ & $\begin{array}{l}13.7 \\
14.4\end{array}$ & $\begin{array}{l}11.9 \\
11.7\end{array}$ & $\begin{array}{l}15.5 \\
13.4\end{array}$ & $\begin{array}{l}13.9 \\
14.0\end{array}$ & $\begin{array}{l}11.5 \\
13.4\end{array}$ & $\begin{array}{l}13.2 \\
14.7\end{array}$ & $\begin{array}{l}14.7 \\
14.1\end{array}$ \\
\hline $\begin{array}{l}\text { 10-year FRS, mean } \\
\text { (SD) }\end{array}$ & $\begin{array}{l}36.1 \pm \\
16.6\end{array}$ & $\begin{array}{l}14.9 \pm 3 \\
.4\end{array}$ & $\begin{array}{l}25.2 \pm \\
2.8\end{array}$ & $\begin{array}{l}46.9 \pm \\
12.8\end{array}$ & $\begin{array}{l}40.37 \\
+18.7\end{array}$ & $\begin{array}{l}15.0 \pm \\
3.5\end{array}$ & $\begin{array}{l}25.1 \pm \\
2.8\end{array}$ & $\begin{array}{l}50.2 \pm 14 \\
.9\end{array}$ \\
\hline
\end{tabular}

Abbreviations: TN: 'Treatment Naïve' group, PT: 'Previous Treatment' group. BMI=Body Mass Index, DBP=Diastolic Blood Pressure, TC: Total Cholesterol, HDL=high density lipoprotein, LDL= low density lipoprotein, SBP=Systolic Blood Pressure, SD=Standard Deviation. FRS: Framingham Risk Score. Bold: $p<0.05$ for the comparison of treatment naïve vs previous treatment. 
Table 2 In-trial characteristics in total cohort and subgroup by 10-year Framingham risk score

\begin{tabular}{|c|c|c|c|c|c|c|c|c|}
\hline \multirow{2}{*}{ Characteristics } & \multicolumn{4}{|c|}{ TN } & \multicolumn{4}{|c|}{ PT } \\
\hline & Total & Low & $\begin{array}{l}\text { Mode } \\
\text { rate }\end{array}$ & High & Total & Low & $\begin{array}{l}\text { Moder } \\
\text { ate }\end{array}$ & High \\
\hline \multicolumn{9}{|l|}{$\begin{array}{l}\text { 2-year BPs, } \\
(\text { mean } \pm \mathrm{SD}, \mathrm{mmHg})^{*} \text { : }\end{array}$} \\
\hline Systolic BP & $\begin{array}{l}136+1 \\
5\end{array}$ & $133+15$ & $\begin{array}{l}136+1 \\
5\end{array}$ & $\begin{array}{l}137 \pm 1 \\
5\end{array}$ & $\begin{array}{l}138 \pm \\
16\end{array}$ & $\begin{array}{l}135 \pm+1 \\
6\end{array}$ & $\begin{array}{l}137 \pm 1 \\
6\end{array}$ & $138 \pm 16$ \\
\hline Diastolic BP & $79 \pm 9$ & $79 \pm 9$ & $80 \pm 10$ & $78+9$ & $79 \pm 10$ & $80 \pm 9$ & $80 \pm 10$ & $79 \pm 10$ \\
\hline $\begin{array}{l}\text { Controlled at }<160 / 90 \text {, } \\
\%\end{array}$ & $83 . \overline{5}$ & 81.8 & 81.5 & 84.8 & 81.2 & 82.0 & 80.4 & 81.3 \\
\hline $\begin{array}{l}\text { Controlled at }<140 / 90 \text {, } \\
\%\end{array}$ & 60.2 & 64.5 & 55.2 & 60.9 & 56.4 & 62.8 & 57.8 & 54.7 \\
\hline $\begin{array}{l}\text { 2-year Medication } \\
\text { Compliance }^{\dagger}, \%\end{array}$ & 71.3 & 72.5 & 70.2 & 71.4 & 72.3 & 72.8 & 71.3 & 72.5 \\
\hline \multicolumn{9}{|l|}{$\begin{array}{l}\text { Number of AHT Meds, } \\
\%\end{array}$} \\
\hline 0 & 9.8 & 10.5 & 9.1 & 9.9 & 3.5 & 3.6 & 3.3 & 3.5 \\
\hline 1 & 66.2 & 70.4 & 67.3 & 64.4 & 53.6 & 61.9 & 57.8 & 50.6 \\
\hline 2 & 18.3 & 14.2 & 18.8 & 19.4 & 29.4 & 25.6 & 27.8 & 30.6 \\
\hline $3+$ & 5.7 & 4.9 & 4.9 & 6.2 & 13.5 & 8.9 & 11.1 & 15.2 \\
\hline \multicolumn{9}{|l|}{$\begin{array}{l}\text { 4-year BPs, (mean } \pm \\
\mathrm{SD}, \mathrm{mmHg})^{*} \text { : }\end{array}$} \\
\hline SBP & $\begin{array}{l}134 \pm \\
15\end{array}$ & $\begin{array}{l}133 \pm \\
16\end{array}$ & $\begin{array}{l}134 \pm \\
16\end{array}$ & $\begin{array}{l}134 \pm \\
145\end{array}$ & $\begin{array}{r}135 \\
+16\end{array}$ & $\begin{array}{l}133 \pm \\
15\end{array}$ & $\begin{array}{l}134 \pm \\
16\end{array}$ & $136 \pm 16$ \\
\hline DBP & $76 \pm 9$ & $78 \pm 9$ & $77 \pm 9$ & $\begin{array}{l}76 \pm \\
10\end{array}$ & $\begin{array}{l}77 \pm \\
10\end{array}$ & $78 \pm 9$ & $78 \pm 9$ & $77 \pm 10$ \\
\hline $\begin{array}{l}\text { Controlled at }<160 / 90 \text {, } \\
\%\end{array}$ & 88.9 & 88.8 & 89.3 & 88.9 & 85.9 & 86.7 & 84.6 & 86.1 \\
\hline $\begin{array}{l}\text { Controlled at }<140 / 90 \text {, } \\
\%\end{array}$ & 68.0 & 67.5 & 67.3 & 68.5 & 64.4 & 69.9 & 65.2 & 63.0 \\
\hline $\begin{array}{l}\text { 48-year Medication } \\
\text { Compliance }{ }^{\dagger}, \%\end{array}$ & 63.5 & 59.1 & 64.7 & 64.4 & 66.6 & 65.1 & 67.1 & 66.8 \\
\hline \multicolumn{9}{|l|}{$\begin{array}{l}\text { Number of AHT Meds, } \\
\%\end{array}$} \\
\hline 0 & 12.2 & 13.8 & 12.1 & 11.7 & 4.5 & 6.0 & 4.5 & 4.1 \\
\hline 1 & 53.9 & 59.2 & 53.5 & 52.3 & 42.6 & 50.2 & 46.9 & 39.6 \\
\hline 2 & 23.9 & 22.0 & 21.6 & 25.4 & 31.2 & 29.2 & 29.7 & 32.1 \\
\hline $3+$ & 10.0 & 5.0 & 12.8 & 10.5 & 21.7 & 14.5 & 18.9 & 24.1 \\
\hline
\end{tabular}

Abbreviations: TN: 'Treatment Naïve' group, PT: 'Previous Treatment' group . AHT=Antihypertensive, $\mathrm{SBP}=$ Systolic Blood Pressure, DBP: Diastolic Blood Pressure, $\mathrm{Hg}=$ Mercury, SD=Standard Deviation. ${ }^{\dagger}$ Compliance $\geq 80 \%$ adherence. Bold: $p<0.05$ for the comparison of treatment naïve vs previous treatment. 
Table 3 Comparison of CVD events and mortality in 'treatment naïve' versus 'previous treated' group in overall population

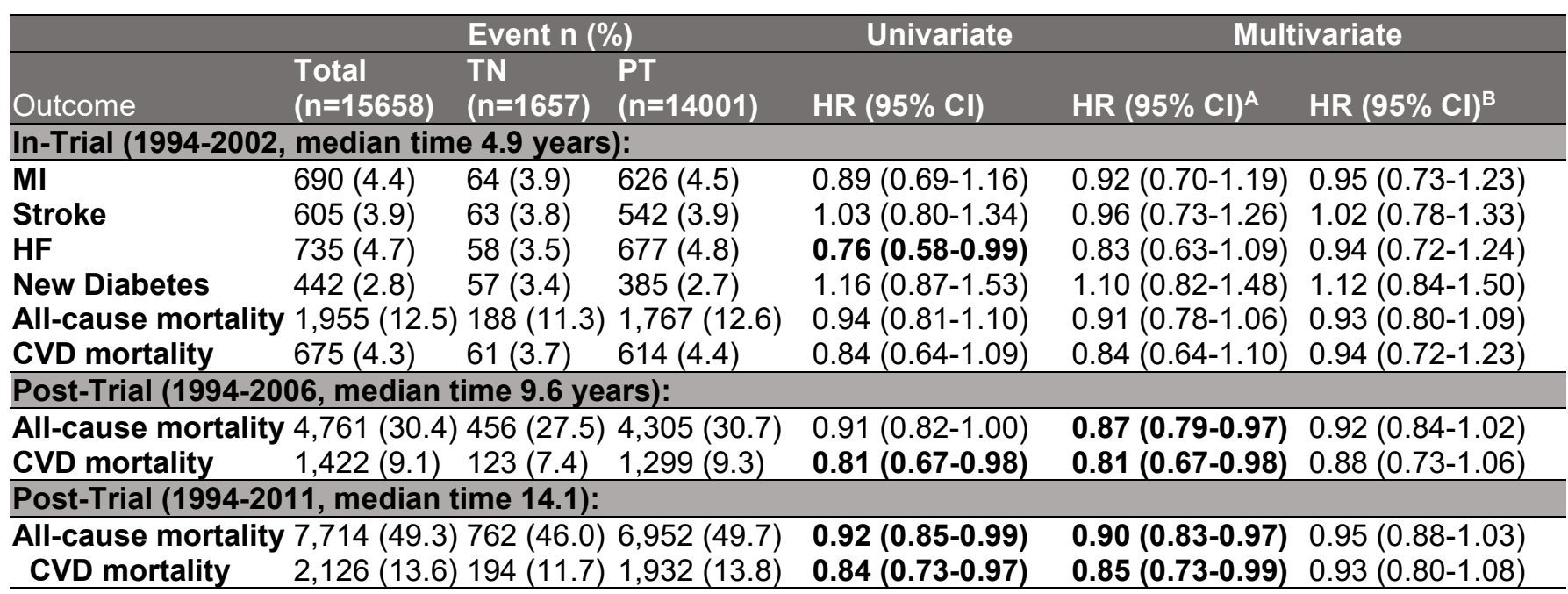

Abbreviations: TN: 'Treatment Naïve' group, PT: 'Previous Treatment' group. MI: Myocardial Infarction. HF: Heart Failure. CVD: Cardiovascular Disease. HR = (Cox proportional) hazard ratio.

Model A: Adjusted for baseline characteristics: age, race, gender, diabetes, education, body mass index, current smoking, aspirin use, randomization group, systolic blood pressure, diastolic blood pressure, total cholesterol, gluco creatinine

Model B: Adjusted for baseline characteristics: age, race, gender, diabetes, education, body mass index, current smoking, aspirin use, total cholesterol, glucose, creatinine plus time-dependent systolic blood pressure and diastolic blood pressure and number of antihypertensive medications. Bold: $p<0.05$ 


\begin{tabular}{|c|c|c|}
\hline \multicolumn{3}{|c|}{$\begin{array}{l}\text { In-trial (1994-2002, median time } 4.9 \text { years) } \\
\text { All-cause mortality }\end{array}$} \\
\hline Low & $148(7.6)$ & $0.65(0,36 \cdot 1.15)$ \\
\hline Moderate & $249(12.7)$ & $1 . \infty(0.66-1.52)$ \\
\hline High & $1558(79.7)$ & $0.89(0.75-1.07)$ \\
\hline $\begin{array}{l}\text { P for interaction } \\
\text { CVD mortality }\end{array}$ & - & NS \\
\hline Low & $41(6.1)$ & $0.62(0.22-1.79)$ \\
\hline Moderate & $75(11.1)$ & $1.55(0.73 \cdot 3.29)$ \\
\hline $\begin{array}{l}\text { High } \\
\text { p for interaction }\end{array}$ & $559(82.8)$ & $\begin{array}{l}0.81(0.59-1.11) \\
\text { NS }\end{array}$ \\
\hline \multicolumn{3}{|c|}{$\begin{array}{l}\text { Post-Trial (1994-2006, median time } 9.6 \text { years): } \\
\text { All-cause mortality }\end{array}$} \\
\hline Low & 349 (7.3) & $0.67(0.46-0.97)$ \\
\hline Moderate & $714(15.0)$ & $0.77(0,59-1 . \infty)$ \\
\hline $\begin{array}{l}\text { High } \\
\text { p for interaction } \\
\text { CVD mortality }\end{array}$ & $3,698(77.7)$ & $\begin{array}{l}0.89(0.79 \cdot 0.99) \\
\text { NS }\end{array}$ \\
\hline Low & $119(6.2)$ & $0.60(0.25-1.43)$ \\
\hline Moderate & $271(14.2)$ & $1.11(0,68=1,81$ \\
\hline High & $1,517(79.6)$ & $\begin{array}{l}0.79(0.64 \cdot 0.99) \\
\text { NS }\end{array}$ \\
\hline \multicolumn{3}{|c|}{$\begin{array}{l}\text { Post-Trial (1994-2011, median time } 14.1 \text { years): } \\
\text { All-cause mortality }\end{array}$} \\
\hline Low & $1,546(19.5)$ & $0.77(0.60-1 . \infty)$ \\
\hline Moderate & $1,963(24.7)$ & $0.75(0.61 \cdot 0.92)$ \\
\hline High & $4,435(55.8)$ & $0.92(0.84-1.01)$ \\
\hline $\begin{array}{l}\text { p for interaction } \\
\text { CVD mortality }\end{array}$ & - & NS \\
\hline Low & $219(7.4)$ & $0.64(0.35 \cdot 1.17)$ \\
\hline High & $2,289(77.7)$ & $0.86(0.72-1.02)$ \\
\hline$p$ for interaction & - & NS \\
\hline
\end{tabular}

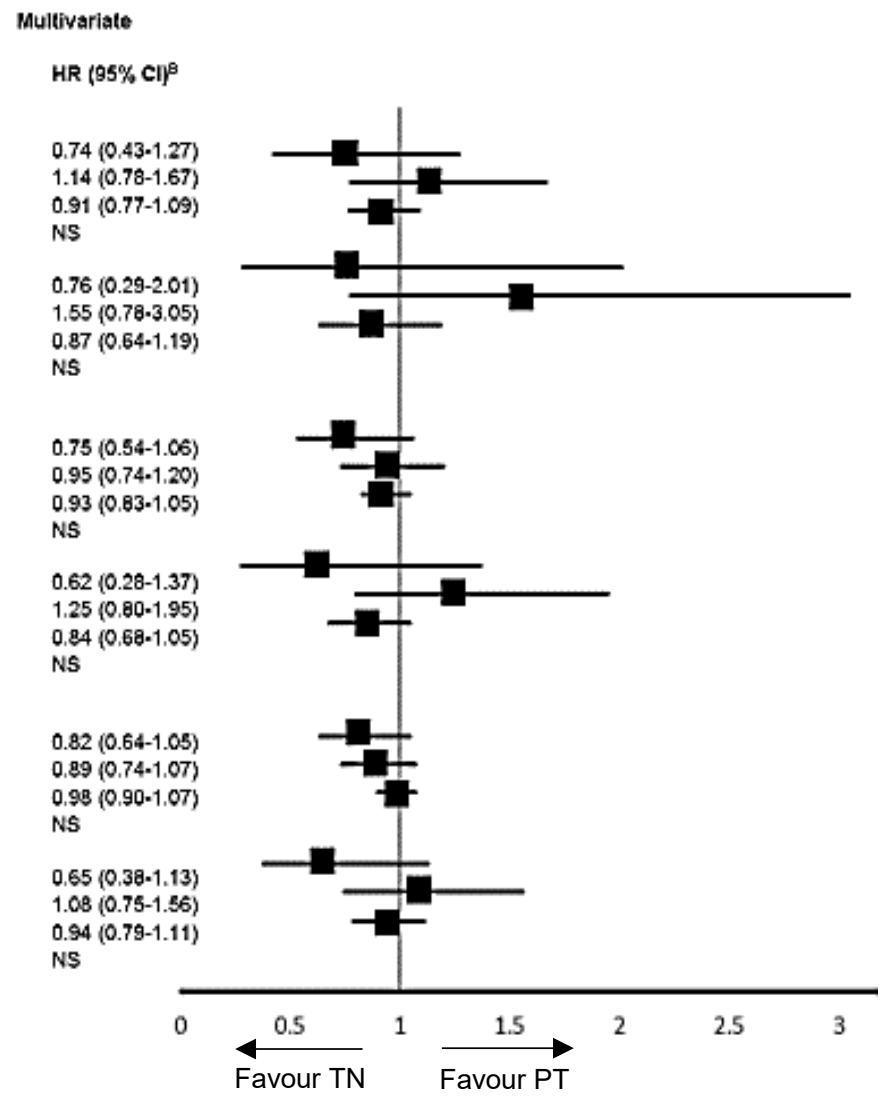

\section{Figure 2. Comparison of CVD events and mortality in 'treatment naïve' versus 'previous treated' in subgroups stratified by 10-year Framingham risk.}

Abbreviations: TN: treatment naïve, PT: previous treatment, CVD: Cardiovascular Disease. $\mathrm{HR}=$ (Cox proportional) hazard ratio.

Model A: Adjusted for baseline characteristics: age, race, gender, diabetes, education, body mass index, current smoking, aspirin use, randomization group, systolic blood pressure, diastolic blood pressure, total cholesterol, glucose, creatinine

Model B: Adjusted for baseline characteristics: age, race, gender, diabetes, education, body mass index, current smoking, aspirin use, total cholesterol, glucose, creatinine plus timedependent systolic blood pressure and diastolic blood pressure and number of antihypertensive medications. Bold: $p<0.05$ 


\section{References}

1. Ministry of Health. Cardiovascular Disease Risk Assessment and Management for Primary Care. Wellington: Ministry of Health; 2018.

2. National Vascular Disease Prevention Alliance. Guidelines for the management of absolute cardiovascular disease risk. 2012.

3. Nerenberg Kara A., Zarnke Kelly B., Leung Alexander A., Dasgupta Kaberi, Butalia Sonia, McBrien Kerry, et al. Hypertension Canada's 2018 Guidelines for Diagnosis, Risk Assessment, Prevention, and Treatment of Hypertension in Adults and Children. Canadian Journal of Cardiology 2018;34(5):506-25.

4. Whelton Paul K., Carey Robert M., Aronow Wilbert S., Casey Donald E., Collins Karen J., Dennison Himmelfarb Cheryl, et al. 2017 ACC/AHA/AAPA/ABC/ACPM/AGS/APhA/ASH/ASPC/NMA/PCNA Guideline for the Prevention, Detection, Evaluation, and Management of High Blood Pressure in Adults. A Report of the American College of Cardiology/American Heart Association Task Force on Clinical Practice Guidelines 2017.

5. Joint British Societies Boards. Joint British Societies' consensus recommendations for the prevention of cardiovascular disease (JBS3). Heart 2014;100(Suppl 2):ii1-ii67.

6. Kostis W. J., Thijs L., Richart T., Kostis J. B., Staessen J. A. Persistence of mortality reduction after the end of randomized therapy in clinical trials of blood pressure-lowering medications. Hypertension 2010;56(6):1060-8.

7. Hirakawa Yoichiro, Arima Hisatomi, Rodgers Anthony, Woodward Mark, Chalmers John. Cumulative in-trial and post-trial effects of blood pressure and lipid lowering: systematic review and meta-analysis. Journal of hypertension 2017;35(5):905-13. 8. Brouwers Fp, Asselbergs Fw, Hillege HI, Boer Ra, Gansevoort Rt, Veldhuisen Dj, et al. Long-term effects of fosinopril and pravastatin on cardiovascular events in subjects with microalbuminuria: ten years of follow-up of Prevention of Renal and Vascular End-stage Disease Intervention Trial (PREVEND IT). American heart journal [serial online] 2011;161(6):1171-8. Available from:

http://onlinelibrary.wiley.com/o/cochrane/clcentral/articles/535/CN$\underline{00799535 / \text { frame.html }}$ 
https://ac-els-cdn-com.ezproxy.utas.edu.au/S0002870311002584/1-s2.0-

S0002870311002584-main.pdf? tid=1069358a-cd15-11e7-8c97-

00000aacb360\&acdnat=1511087781 3068cf89069d36c5e30b8ec9ac1be55a.

9. Asselbergs Folkert W, Diercks Gilles FH, Hillege Hans L, van Boven Ad J, Janssen Wilbert MT, Voors Adriaan A, et al. Effects of fosinopril and pravastatin on cardiovascular events in subjects with microalbuminuria. Circulation 2004;110(18):2809-16.

10. Leren Paul, Helgeland Anders. Coronary heart disease and treatment of hypertension some Oslo study data. The American journal of medicine 1986;80(2):36.

11. Helgeland Anders. Treatment of mild hypertension: a five year controlled drug trial: the Oslo study. The American journal of medicine 1980;69(5):725-32.

12. Nelson Mark R. a, Chowdhury Enayet K. b, Doust Jenny c, Reid Christopher M. b d, Wing Lindon M. H. e. Ten-year legacy effects of baseline blood pressure 'treatment naivety' in the Second Australian National Blood Pressure study. Journal of Hypertension.

13. The Allhat Officers and Coordinators for the Allhat Collaborative Research Group. Major outcomes in high-risk hypertensive patients randomized to angiotensin-converting enzyme inhibitor or calcium channel blocker vs diuretic: The antihypertensive and lipid-lowering treatment to prevent heart attack trial (allhat). JAMA 2002;288(23):2981-97.

14. Barzilay Joshua I, Davis Barry R, Pressel Sara L, Cutler Jeffrey A, Einhorn Paula T, Black Henry R, et al. Long-term effects of incident diabetes mellitus on cardiovascular outcomes in people treated for hypertension: the ALLHAT Diabetes Extension Study. Circ Cardiovasc Qual Outcomes 2012:CIRCOUTCOMES. 111.962522.

15. D'Agostino Ralph B., Vasan Ramachandran S., Pencina Michael J., Wolf Philip A., Cobain Mark, Massaro Joseph M., et al. General Cardiovascular Risk Profile for Use in Primary Care. The Framingham Heart Study 2008;117(6):743-53.

16. Vanuzzo Diego. The epidemiological concept of residual risk. Intern Emerg Med 2011;6(1):45.

17. Asayama Kei, Satoh Michihiro, Murakami Yoshitaka, Ohkubo Takayoshi, Nagasawa Sin-ya, Tsuji Ichiro, et al. Cardiovascular risk with and without 
antihypertensive drug treatment in the Japanese general population: participant-level meta-analysis. Hypertension 2014;63(6):1189-97.

18. Blacher J, Evans A, Arveiler D, Amouyel P, Ferrieres J, Bingham A, et al. Residual cardiovascular risk in treated hypertension and hyperlipidaemia: the PRIME Study. Journal of human hypertension 2010;24(1):19.

19. Lieb Wolfgang, Enserro Danielle M, Sullivan Lisa M, Vasan Ramachandran S. Residual Cardiovascular Risk in Individuals on Blood Pressure-Lowering Treatment. Journal of the American Heart Association 2015;4(11):e002155.

20. Thomopoulos Costas, Parati Gianfranco, Zanchetti Alberto. Effects of blood pressure lowering on outcome incidence in hypertension: 3 . Effects in patients at different levels of cardiovascular risk-overview and meta-analyses of randomized trials. Journal of hypertension 2014;32(12):2305-14.

21. Lonn Eva M, Bosch Jackie, López-Jaramillo Patricio, Zhu Jun, Liu Lisheng, Pais Prem, et al. Blood-pressure lowering in intermediate-risk persons without cardiovascular disease. New England Journal of Medicine 2016;374(21):2009-20. 